\title{
Effectiveness of interventions to prevent mother-to-child transmission of HIV in Southern Ethiopia
}

This article was published in the following Dove Press journal:

International Journal of Women's Health

2 November $201 \mathrm{I}$

Number of times this article has been viewed

\author{
Behailu Merdekios' \\ Adebola A Adedimeji ${ }^{2}$ \\ 'College of Medicine and Health \\ Sciences, Arba Minch University, \\ Ethiopia; ${ }^{2}$ Albert Einstein College \\ of Medicine, Jack and Pearl Resnick \\ Campus, New York, USA
}

\begin{abstract}
Background: In Ethiopia, Progress in Reducing Mother-to-Child-Transmission (PMTCT) of human immunodeficiency virus (HIV) is being curtailed by behavioral and cultural factors that continue to put unborn children at risk, and mother-to-child transmission is responsible for more than $90 \%$ of HIV infection in children. The objective of this study was to assess PMTCT services by examining knowledge about reducing vertical transmission among pregnant women.

Methods: A multistaged sampling institution-based survey was conducted in 113 pregnant women in Arba Minch. Qualitative and quantitative data were obtained.

Results: Of the 113 respondents, 89.4\% were from Arba Minch, 43.4\% were at least 25 years of age, $73.4 \%$ had formal education at primary level or above, $100 \%$ reported acceptance of voluntary counseling and testing, $92.0 \%$ were knowledgeable about mother-to-child transmission, and $90.3 \%$ were aware of the availability of the PMTCT service in the health facility. Of 74 HIV-positive women in PMTCT, only three (4.1\%) had had skilled birth attendants at delivery. There was an unacceptable degree of loss of women from PMTCT. Maternal educational level had a statistical association with income $(P<0.001)$ and voluntary counseling and testing for pregnant women $(P<0.05)$. Factors that determined use of PMTCT included culture, socioeconomic status, and fear of stigma and discrimination.
\end{abstract}

Conclusion: In the area studied, intervention to reduce mother-to-child transmission of HIV is failing to reach its goal. This is an alarming discovery requiring quick reconsideration and strengthening of preventive strategies at all levels.

Keywords: human immunodeficiency virus, mother-to-child transmission, pregnant women, Ethiopia

\section{Introduction}

Since 1981, when acquired immunodeficiency syndrome (AIDS) first emerged, more than 25,000,000 people have died of AIDS-related diseases globally. Around 2.1 million men, women, and children lost their lives as a result of AIDS in 2007 alone. Currently, 33.2 million people of all age groups are living with human immunodeficiency virus (HIV). Sub-Saharan Africa remains the worst affected region in the global AIDS epidemic. Devastatingly, the epidemic has also impacted children, and has created an estimated 11.4 million orphans. According to a Joint United Nations Programme on HIV and AIDS report, the HIV epidemic in Africa is following divergent trends. ${ }^{1}$ The Ethiopian Federal Ministry of Health has documented that "HIV was first detected in Ethiopia in 1984 and the first two AIDS cases were reported in 1986."2

Based on data from sentinel antenatal care sites, the HIV/AIDS prevalence estimate for adult Ethiopians aged 15-49 years is 2.1\%. ${ }^{3}$ At the time of this study, there 
were 399 Progress in Reducing Mother-to-Child-Transmission (PMTCT) sites located around the country. Of these, 63 $(15.6 \%)$ are found in the Southern Nations, Nationalities and Peoples' Region and four are located in the Gamo Goffa Zone. ${ }^{4}$ It is estimated that 800,000 infants were infected with HIV via mother-to-child transmission in 2001, almost $90 \%$ of them in Sub-Saharan Africa. ${ }^{5}$ The increasing number of women living with HIV worldwide makes prevention critical, not only for the sake of women's health but also to reduce future HIV infection among infants in sub-Saharan Africa, where half the female population is of childbearing age. ${ }^{6}$

There are factors that determine the awareness of pregnant women about voluntary counseling and testing services. Although voluntary counseling and testing is widely accepted, there are progressive and unacceptable losses to follow-up of $55 \%, 68 \%$, and $70 \%$ of HIV-positive mothers during the antenatal period, delivery, and first postnatal visits, respectively. Moreover, a great majority of deliveries occur at peripheral sites where PMTCT is not available, ${ }^{7}$ and it has been reported that antenatal clients aged 15-24 years have the highest prevalence $(5.6 \%)$ of all age groups in Ethiopia. ${ }^{8}$ A study done in the Temeke district, Tanzania, showed that one of the factors that determines prenatal HIV testing for PMTCT was awareness of pregnant women about the program. ${ }^{9}$ In another similar study done in Ethiopia, mothers from Addis Ababa with a secondary educational level or above were found to be more knowledgeable about mother-to-child transmission and PMTCT, while only a very small proportion knew about elective caesarean section as a preventive method. ${ }^{10}$

Globally, as few as one-third of deliveries are taking place in health facilities, and up to around 60 million women each year are attended by an unskilled birth attendant or nobody at all at delivery. ${ }^{11}$ In Ethiopia, a larger percentage of teenage mothers report home delivery, which is mainly due to a poor socioeconomic background and illiteracy. ${ }^{12}$

The rate of transmission of HIV from pregnant women to their babies has decreased to less than $2 \%$ in industrialized countries. Despite these isolated successes, access to PMTCT services remains unsatisfactorily low in many countries, with only about $2 \%$ of women globally who qualify for PMTCT services being able to access it. This is either because they do not know their HIV status or because PMTCT interventions are not available to them. Without intervention, the risk of transmission remains high. ${ }^{13}$ In Ethiopia, there are no reliable and comprehensive data on mother-to-child transmission, and the only relevant study performed to date has crudely estimated the rate of vertical transmission among HIV-infected pregnant women to be over $29 \%$. While no reliable information is available on mother-to-child transmission of HIV, all major protective parameters during pregnancy and delivery, including availability of family planning services, provision of antiretroviral drugs to mothers and their newborns, safe delivery, and counseling and support regarding infant feeding are deficient in Ethiopia. ${ }^{14}$ The World Health Organisation recommends "exclusive breast-feeding by HIV-infected mothers in countries with high infant mortality rates where replacement feeding is generally not affordable feasible, acceptable, sustainable or safe, as in much of Ethiopia." 15

Health facility-based deliveries were significantly lower among mothers in rural areas compared with those in the urban setting." 16 Similarly, analysis of PMTCT services in three Sub-Saharan African countries has shown that "the percentage of HIV-positive women missed by the PMTCT program was $17 \%$ in Kenya, 57\% in Ethiopia, and 58\% in Zimbabwe." 17 Therefore, we conducted this study to assess the effectiveness of PMTCT services, with emphasis on the level of antenatal/voluntary counseling and testing/delivery/ antiretroviral service uptake by HIV-positive pregnant women attending public health facilities in Arba Minch in the Southern Nations, Nationalities and Peoples' Regional State.

\section{Materials and methods}

This study was conducted in two public health facilities, ie, a district hospital and a health center in Arba Minch, the capital of Gamo Goffa zone, from April 1 to June 30, 2009. This town has an estimated 120,000 residents. The two facilities are well organized in terms of resources to run PMTCT services. These facilities are providing services to more than 1.5 million inhabitants in the area.

A descriptive, institution-based, cross-sectional study design was used, and facilities were selected using multistage sampling. The sample size was determined using the formula for cross-sectional studies, ${ }^{18}$ with the expected population proportion at $50 \%$ at $95 \%$ confidence intervals [CI]. Accordingly, a total sample size of 113 was considered. Both quantitative and qualitative data were obtained. The quantitative method comprised a pretested and well structured questionnaire for pregnant women attending antenatal care and review of labor and delivery records of women enrolled in PMTCT. The qualitative data were obtained using two of eight focus group discussion participants who were health workers from each health facility and were currently working in and around PMTCT service in the facilities. Focus group participants were selected based on a set of selection criteria for homogeneity. 
Data were cleaned, edited, and entered into a computer and analyzed using the Statistical Package for Social Sciences Version 14.0 (SPSS Inc, Chicago, IL). The focus group discussion was recorded using a digital sound recorder, translated into the English language, and then transcribed. Finally, after thematic areas were outlined based on the variables, direct quotations were used to explain issues that were not addressed in the questionnaire.

Data were collected after obtaining ethical approval from the Faculty of Medicine and Primary Health Care, Trinity College, Dublin, Ireland, followed by the Southern Nations, Nationalities and Peoples' Regional Health Bureau, and written consent if applicable. Verbal consent was obtained from all the study participants.

\section{Results}

A total of 113 pregnant women participated in this study, with a $100 \%$ response rate. Fifty-seven percent of the women were from Arba Minch township while the rest were from neighboring villages. In terms of location of antenatal care, $43 \%$ attended Arba Minch Hospital and 57\% attended the Health Center. Forty-nine women (43.5\%) were over the age of 25 years, 34 (30.1\%) were aged 15-19 years, and 30 were aged $20-24$ years (26.5\%). Of the total number of women, $30(26.5 \%)$ were in employment, of whom $16(53.3 \%)$ were public employees and the remaining $14(46.7 \%)$ were self-employed, with a considerable proportion being unemployed (83, 73.5\%). Results for educational status showed that most of the women had had a formal education $(83,73.5 \%)$, of whom $15(18.1 \%)$ had a college diploma, 37 (44.6\%) had attended to the level of junior secondary school (grade 7-8), and 31 (37.3\%) had attained a primary level of schooling (grade $1-6)$. The remaining 30 (26.5\%) were uneducated. With regard to monthly income, 35 (31.0\%) of the women had a monthly income of less than 320 Ethiopian Birr, with the highest income group earning 752-7168 Ethiopian Birr per month (Table 1).

Table I Sociodemographic characteristics of the study population $(n=1$ I3) by health facility in Arba Minch, April-June, 2008

\begin{tabular}{|c|c|c|c|}
\hline \multirow[t]{2}{*}{ Variables } & \multicolumn{2}{|l|}{ Health facility } & \multirow[t]{2}{*}{ Total (\%) } \\
\hline & $\begin{array}{l}\text { Arba Minch Hospital } \\
\text { (\%) } n=49\end{array}$ & $\begin{array}{l}\text { Arba Minch Health Center } \\
\text { (\%) } n=64\end{array}$ & \\
\hline \multicolumn{4}{|l|}{ Age, years } \\
\hline $15-19$ & $12(24.5)$ & $22(34.4)$ & $34(30.1)$ \\
\hline $20-24$ & $10(20.4)$ & $20(3 \mid .2)$ & $30(26.5)$ \\
\hline$\geq 25$ & $27(55.1)$ & $22(34.4)$ & $49(43.4)$ \\
\hline \multicolumn{4}{|l|}{ Last educational level completed } \\
\hline Illiterate & $12(24.5)$ & $18(28.1)$ & $30(26.5)$ \\
\hline Primary school (grade I-6) & $13(26.5)$ & $18(28.1)$ & $31(27.4)$ \\
\hline Junior schooling (grade 7-8) & $16(32.7)$ & $21(32.8)$ & 37 (32.7) \\
\hline College level & $8(16.3)$ & $7(10.9)$ & $15(13.3)$ \\
\hline University and above & 0 & 0 & 0 \\
\hline \multicolumn{4}{|l|}{ Religion } \\
\hline Protestant & $19(38.8)$ & $33(5 \mathrm{I} .6)$ & $52(46.0)$ \\
\hline Orthodox & $26(53.1)$ & $26(40.6)$ & $52(46.0)$ \\
\hline Muslim & $3(6.1)$ & $3(4.7)$ & $6(5.3)$ \\
\hline Others* & I (2.0) & $2(3.1)$ & $3(2.7)$ \\
\hline \multicolumn{4}{|l|}{ Monthly income (Ethiopian Birr) } \\
\hline$\leq 320$ & $17(34.7)$ & $18(28.1)$ & $35(31.0)$ \\
\hline $320-727$ & $12(24.5)$ & $29(45.3)$ & $41(36.3)$ \\
\hline $763-3597$ & $18(36.7)$ & $15(23.4)$ & $33(29.2)$ \\
\hline $3752-7168$ & $2(4.1)$ & $\mathrm{I}(\mathrm{I} .6)$ & $3(2.7)$ \\
\hline$>7168$ & 0 & I (I.6) & $\mathrm{I}(0.9)$ \\
\hline \multicolumn{4}{|l|}{ Number of live children at home } \\
\hline First pregnancy & $16(32.7)$ & $38(59.4)$ & $54(47.8)$ \\
\hline I-2 live children & $18(36.7)$ & $21(32.8)$ & $39(34.5)$ \\
\hline 3-4 live children & $9(18.4)$ & $3(4.7)$ & $12(10.6)$ \\
\hline$\geq 5$ live children & $6(12.2)$ & $2(3.1)$ & $8(7.1)$ \\
\hline \multicolumn{4}{|l|}{ Marital status } \\
\hline Married and living together & $47(95.9)$ & $59(92.2)$ & $106(93.8)$ \\
\hline Married but living alone & I (2.05) & $3(4.7)$ & $4(3.5)$ \\
\hline Single & I (2.05) & $2(3.1)$ & $3(2.7)$ \\
\hline
\end{tabular}


All of the study participants understood that testing blood for HIV is essential for pregnant women, but very few understood the rationale for this. Fifty-eight women (51.3\%) said it was important to "know self" and 31 (27.4\%) said "to know self, prevent the transmission to the fetus/child and to take the necessary precautions in my future life." In total, 104 (92.0\%) women knew that HIV can be transmitted from an infected woman to her unborn child, and 102 (90.3\%) knew that PMTCT services were available in the health facilities. Twenty-seven (26.5\%) women recalled only two of the known preventive measures advocated by PMTCT services, ie, use of available prophylactic antiretroviral therapy and avoiding breast-feeding of a newborn baby. Meanwhile, 20 (17.7\%) women explained that mother-to-child transmission of HIV could be prevented solely by avoiding breast-feeding and $17(15.0 \%)$ were aware that delivery in a health facility, use of available antiretroviral therapy, and avoiding breastfeeding were all measures that could prevent mother-to-child transmission of HIV. In summary, only seven (6.2\%) of the participating pregnant women were fully knowledgeable about PMTCT services (Figure 1).
No statistical association between maternal educational level and knowledge of availability of PMTCT services at health facilities was found $(P=0.549,95 \% \mathrm{CI})$. In contrast, the maternal education level was significantly associated with monthly income and knowledge about the importance of voluntary counseling and testing for HIV, with $P$ values of 0.000 and $0.021,95 \% \mathrm{CI}$, respectively (Tables 3 and 4 ).

Regarding attitudes, 110 (97.3\%) responded positively to advice given by health workers, and had either already undergone or were willing to undergo HIV testing. Eightyfour $(74.3 \%)$ women were willing to give advice to any HIVpositive pregnant woman regarding the availability of PMTCT services and the importance of follow-up, while 26 (23.0\%) stated they would never attempt to do so (Table 1).

The review of secondary data for Arba Minch Hospital revealed that during the previous Ethiopian fiscal year (ie, 2007), a total of 35 HIV-positive pregnant women were recorded as attending the antenatal clinic, who were then enrolled as PMTCT clients and put on antiretroviral therapy. When examining the PMTCT register for labor and delivery, there were 26 deliveries for HIV-positive women. However,

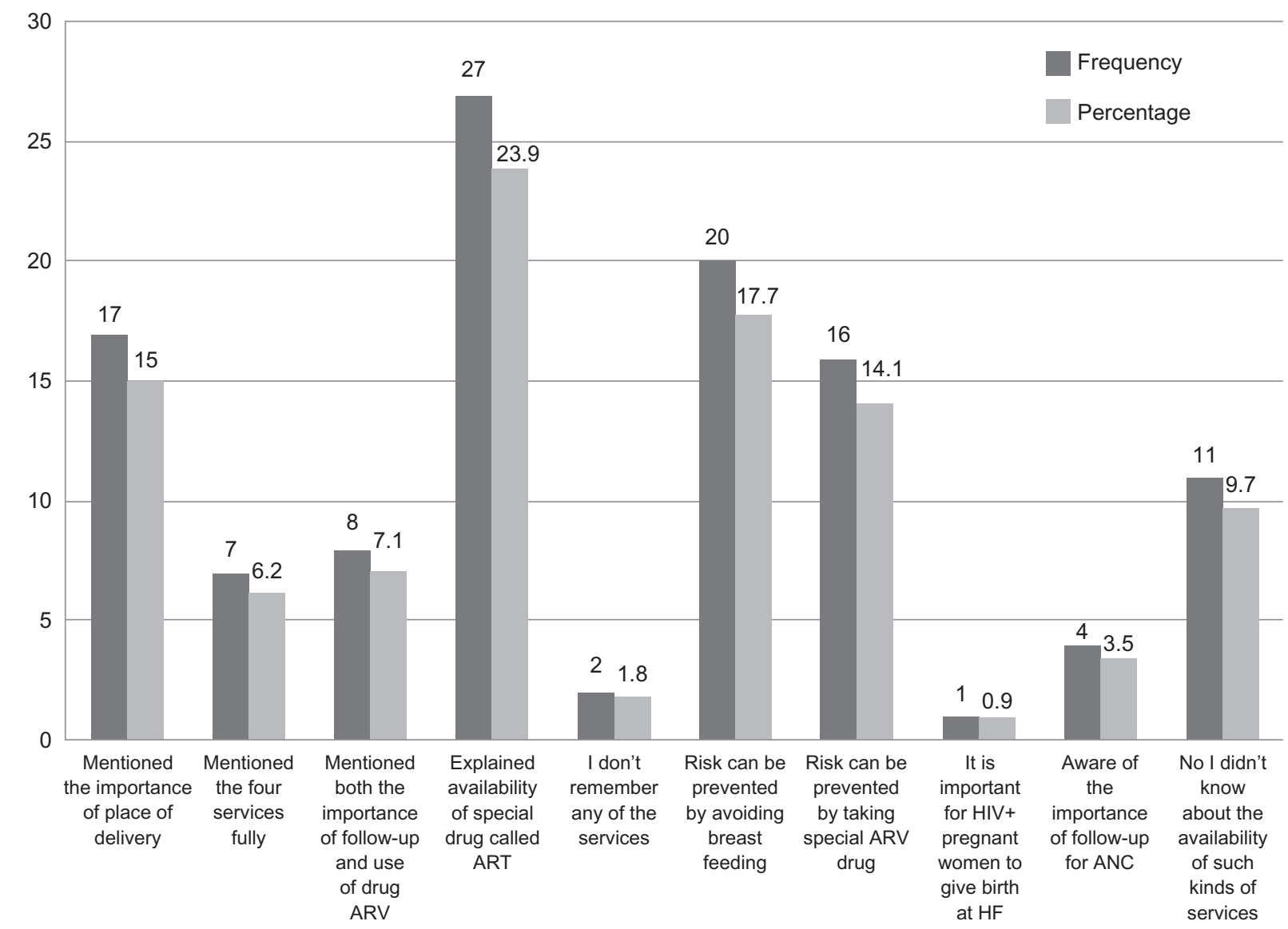

Figure I Knowledge of study population ( $\mathrm{n}=$ II3) about types of services for Progress in Reducing Mother-to-Child-Transmission of HIV in Arba Minch, April-June 2009. Abbreviations: ART, antiretroviral therapy; ARV, antiretroviral; ANC, antenatal clinics, HF, health facility. 
none of the mothers who were registered in the PMTCT at the antenatal clinic had given birth at this health facility.

The verbatim response of one of the focus group discussion participants to the question "Do all HIV-positive pregnant women who were enrolled in PMTCT service at the antenatal clinic come to your facility for delivery?" was: "No, because first, fear of the women in labor to be seen by their accompanying relatives, friends or neighbors, and secondly, they frequently change their address, as many of them are from a low socio-economic background and they can't afford the service charge for delivery."

To the question "Have you tried to reach those women who were lost from PMTCT and institutional delivery?" one response was: "We should have at least tried to contact any dropouts according to their contact address details or we could have called via telephone or even walked to their residence."

The HIV-positive women not enrolled for PMTCT who gave birth in the hospital either came from different health facilities in the town, health facilities from out of town, or were newly diagnosed at the hospital using providerinitiated HIV counseling and testing when they appeared at the hospital with labor pains. Nothing is known about the outcomes for those women diagnosed as HIV-positive during antenatal visits who did not return to the hospital to give birth. One focus group participant said: "If there were well certified community health workers in the town, a community networking strategy could be established and it would have been more easier for health workers to find defaulting women."

Monitoring of PMTCT was not good, according to one of the focus group participants: "The work of departments involved in PMTCT such as the ANC, antiretroviral therapy, PMTCT and labor and delivery rooms should have regular feedback on the updates of their activity. But this is not happening in our hospital." The fact that the 26 women who came in with labor pains for delivery at the facility were diagnosed after provider-initiated HIV counseling and testing suggests clearly that HIV is a problem in pregnant women (Table 2).

Likewise, at the Arba Minch Health Center, there were 39 HIV-positive pregnancies diagnosed at the antenatal clinic, who were then enrolled as PMTCT clients and put on antiretroviral therapy. Examination of the PMTCT register from the labor and delivery ward showed that there were five HIV-positive deliveries, of which only three were for pregnant women enrolled at the PMTCT service during their pregnancies. In the health center, no information was available about the women who were diagnosed as HIV-positive and enrolled in PMTCT and the mothers' support group but did not return to the health center for delivery.

Regarding the overall effectiveness of the implementation of the prevention program, a participant from the Arba Minch Health Center said: "It is now five years since we've started PMTCT. But after five years of intervention period, as far as HIV free children born to HIV positive women is concerned, only four children were declared HIV free, which is very little."

\section{Discussion}

In this study, it is demonstrated clearly that voluntary counseling and testing is acceptable to pregnant women and well adopted by study participants. Correspondingly, $110(97.3 \%)$ of the pregnant participants in this study had undergone voluntary counseling and testing or had agreed to do so at the time of the study. The high level of awareness of voluntary counseling and testing and its uptake among our participants was different from that reported

Table 2 Secondary quantitative data by age of women and health facility in Arba Minch, April-June, 2009

\begin{tabular}{|c|c|c|c|c|c|c|}
\hline \multirow[t]{2}{*}{ Variable } & \multicolumn{2}{|c|}{$\begin{array}{l}\text { HIV+ pregnant women } \\
\text { enrolled in ANC PMTCT (n) }\end{array}$} & \multicolumn{2}{|c|}{$\begin{array}{l}\text { HIV+ deliveries attended by a } \\
\text { skilled person from the } \\
\text { respective } \\
\text { PMTCT service }(\mathrm{n})\end{array}$} & \multicolumn{2}{|c|}{$\begin{array}{l}\text { Skilled person attended } \\
\text { deliveries in health facility by } \\
\text { HIV+ women outside PMTCT (n) }\end{array}$} \\
\hline & $\begin{array}{l}\text { Arba Minch } \\
\text { Hospital }\end{array}$ & Arba Minch HC & $\begin{array}{l}\text { Arba Minch } \\
\text { Hospital }\end{array}$ & Arba Minch HC & $\begin{array}{l}\text { Arba Minch } \\
\text { Hospital }\end{array}$ & Arba Minch HC \\
\hline \multicolumn{7}{|c|}{ Age group, years } \\
\hline $15-19$ & 5 & 7 & 0 & 1 & 5 & 0 \\
\hline $20-24$ & 13 & 14 & 0 & I & 2 & 1 \\
\hline $25-29$ & 9 & II & 0 & I & 8 & I \\
\hline $30-34$ & 7 & 6 & 0 & 0 & 7 & 0 \\
\hline$\geq 35$ & 1 & 1 & 0 & 0 & 4 & 0 \\
\hline Total & 35 & 39 & 0 & 3 & 26 & 2 \\
\hline
\end{tabular}

Abbreviations: ANC, antenatal clinic; HC, Health Center; HIV+ human immunodeficiency virus positive; PMTCT, Progress in Reducing Mother-to-Child-Transmission. 
Table 3 Association of maternal education level with knowledge of availability of PMTCT services in public health facilities in Arba Minch, April-June 2008

\begin{tabular}{llllll}
\hline Variables & \multicolumn{2}{l}{ Last educational level completed } & & Total \\
\cline { 2 - 5 } & Illiterate & Primary school & Junior and high school & College level \\
\hline Knowledge of availability of PMTCT services inhealth facility & & 34 & 15 & 102 \\
Yes & 26 & 27 & 3 & 0 & 11 \\
No & 4 & 4 & 37 & 15 & 113 \\
Total & 30 & 31 & &
\end{tabular}

Notes: $\chi^{2}=2.525 ; P>0.05 ; \mathrm{Df}=3$; confidence interval $95 \%$.

Abbreviation: PMTCT, Progress in Reducing Mother-to-Child-Transmission.

by Amberbir et al, ${ }^{19}$ but consistent with a report from the Ethiopian HIV/AIDS Prevention and Control Office..$^{20}$ Our study findings are comparable with those of similar studies in Malawi (96\%), ${ }^{8}$ Addis Ababa (76.8\%), ${ }^{10}$ and Abidjan, Cote d'Ivoire (80.1\%). ${ }^{21}$ Women's knowledge about the possibility of transmission of HIV from an infected woman to her fetus is incompatible with their knowledge of why voluntary counseling and testing is important in pregnancy. Pregnant women who responded that they should have testing for the sake of knowing their own HIV status did not show an understanding of the importance of voluntary counseling and testing during pregnancy. This indicates that women need to be well informed about the possibility of transmission of HIV across the placental barrier to increase their confidence in voluntary counseling and testing.

In this study, women with a primary educational background and above were found to be more knowledgeable about the importance of HIV testing in pregnant women and PMTCT. This finding is consistent with the findings of a study by Jebessa and Teka. ${ }^{10}$ Acceptance of voluntary counseling and testing in this study was $100 \%$, which is consistent with the results of research in other developing countries. $^{22}$

Comprehensive knowledge about HIV is critical for effective implementation of PMTCT programs in pregnant populations of women. A greater proportion of the study population had demonstrated knowledge about transmission of HIV from an infected mother to her baby (90.3\%), and these findings are comparable with the findings of $80.0 \%$ and $89.8 \%$ in two studies conducted in Ethiopia. ${ }^{911} \mathrm{~A}$ unique finding in this study was that $90.3 \%$ of women were aware of the availability of PMTCT services, which is quite high when compared with the finding of $20.0 \%$ from the same facilities in $2003 .^{8}$

Antenatal care coverage has reached nearly half of the pregnant population nationally, and of these, only $16 \%$ of births are attended by skilled personnel..$^{2}$ In a study conducted in north Gondar, located in north-western Ethiopia, maternal educational level was found to be a strong predictor of preference for place of delivery. ${ }^{23}$ However, this appears to be contrary to the findings among pregnant HIV-positive women in this study. Cultural influences, poor socioeconomic status, and fear of the stigma associated with an HIV-positive status are factors that influence choice of delivery location, irrespective of maternal educational level.

The revised Health Sector Development Plan III of Ethiopia $^{3}$ envisages a new strategy for boosting health service coverage using a health extension program. This program involves training female health extension workers to work in the rural villages, with 16 specific health

Table 4 Association of maternal education level with monthly income of study population $(n=1$ I3) in Arba Minch, April-June 2008

\begin{tabular}{|c|c|c|c|c|c|}
\hline \multirow[t]{2}{*}{ Variables } & \multicolumn{4}{|c|}{ Last educational level completed } & \multirow[t]{2}{*}{ Total } \\
\hline & Illiterate & Primary school & $\begin{array}{l}\text { Junior and high } \\
\text { school }\end{array}$ & College level & \\
\hline \multicolumn{6}{|c|}{ Monthly income in Ethiopian Birr } \\
\hline$<320$ & 19 & 10 & 6 & 0 & 35 \\
\hline $320-727$ & 9 & 16 & 13 & 3 & 41 \\
\hline $763-3597$ & 2 & 5 & 16 & 10 & 33 \\
\hline $3752-7168$ & 0 & 0 & 1 & 2 & 3 \\
\hline$>7168$ & 0 & 0 & 1 & 0 & I \\
\hline Total & 30 & 31 & 37 & 15 & I \\
\hline
\end{tabular}

Notes: $\chi^{2}=47.705$, Fisher's exact test $=44.102 ; \mathrm{Df}=12 ; \mathrm{Cl}=95 \% ; P<0.000 \mathrm{I}$. 
packages that are considered essential for improving the health conditions of a rural community. Since its implementation, it is being seen that the health extension workers are changing the health-seeking knowledge and behavior of the community and improving the health status of the rural population they serve. This is making a remarkable contribution to achieving the objectives of Health Sector Development Plan III and the Millennium Development Goals. This strategy, if applied in urban settings, where HIV prevalence is as high as $10.5 \%,{ }^{2}$ could benefit the urban poor and could help trace women lost from PMTCT. Therefore, there is a need to scale up the health extension program to urban settings. In the focus group discussion component of this study, it was clearly stated that urban health extension workers could help in approaching women who had disappeared from PMTCT follow-up in their homes.

A woman in labor being accompanied by older relatives and neighbors until the newborn's umbilical cord is buried is a very common tradition throughout Ethiopia. The fear of being seen by relatives and friends while taking antiretroviral tablets is one of the reasons why they do not return for an institutional delivery. Therefore, home deliveries are seen as an excuse to avoid the stigma and risk of marital breakdown associated with disclosure of an HIV-positive status. The preference of women for traditional birth attendants is not irrational. When a woman goes into labor, traditional birth attendants can be accessed easily, immediately, and with minimal fees for service, and provide psychological support to help the woman to remain comfortable during the birthing process.

Review of records revealed that there were 74 HIVpositive pregnancies diagnosed (35 at hospital and 39 at the health center) and integrated into PMTCT services. Meanwhile, there were only 31 HIV-positive deliveries at both health facilities. An alarming finding of this study was that only three $(4.1 \%)$ of the 74 HIV-positive women registered for PMTCT services returned to the health facility for an institutional delivery where pediatric antiretroviral therapy could have been provided for their babies. The remaining $71(95.9 \%)$ of HIV-positive women who might have received antiretroviral therapy and had a routine follow-up did not return for an institutional delivery, and nothing is known about the outcomes of those pregnancies or the HIV status of the newborns. This wide gap between the number of women involved in the PMTCT service, including follow-up, and those who return for delivery as expected must be addressed.
The quality and effectiveness of PMTCT services should be assessed on the basis of the number of mother-child pairs who are receiving consistent follow-up and antiretroviral treatment, and the number of confirmed HIV-negative children born to HIV-positive women. Identification of HIV-positive pregnancies and linking them to antiretroviral therapy and follow-up alone cannot be sufficient for effectiveness of PMTCT program. This is one of the major findings of this paper, highlighting new knowledge about PMTCT services in Arba Minch. Meticulous scrutiny of existing PMTCT strategies in the Zone, Woreda and Region is mandatory to scale up PMTCT services. Without prompt attention, the catastrophic loss of the most disadvantaged part of our population, ie, women and children, will be inevitable.

\section{Acknowledgments}

Irish Aid is thanked for its financial support of this research, as is the Southern Nations Nationalities and Peoples' Regional Health Bureau, as well as the two health facilities in Arba Minch, and all the women and health workers who participated in this study.

\section{Disclosure}

The authors report no conflicts of interest in this work.

\section{References}

1. Joint United Nations Programme on HIV/AIDS/World Health Organisation. AIDS epidemic update. Towards universal access; scaling up priority HIV/AIDS interventions in the health sector. Progress report 2008. Available from: http://www.who.int/hiv/pub/towards universal_access_report_2008.pdf. Accessed July 8, 2008.

2 Ethiopian Federal Ministry of Health. AIDS in Ethiopia: The sixth report. Addis Ababa, Ethiopia: Ethiopian Ministry of Health; 2006.

3. Ethiopian Federal Ministry of Health. 2007: Annual report of HSDP III. Addis Ababa, Ethiopia: Ethiopian Ministry of Health; 2006.

4. AIDS Resource Centre. PMTCT sites in Ethiopia. Available from: http:// www.etharc.org/. Accessed June 19, 2008.

5. Moore M. A Behaviour Change Perspective on Integrating PMTCT and Safe Motherhood Programs: A Discussion Paper. Washington DC: The CHANGE Project and AED/The Manoff Group; 2003. Available from: http://www.aed.org/Publications/upload/PMTCT-SafeMotherhood.pdf. Accessed September 27, 2011.

6. Newell ML. Prevention of mother-to-child transmission of HIV: Challenges for the current decade: Bull World Health Organ. 2001;79(12):1138-1144.

7. Manzi M, Zachariah R, Teck R, et al. High acceptability of voluntary counselling and HIV testing but unacceptable loss to follow-up in a prevention of mother-to-child HIV transmission programme in rural Malawi: Scaling-up requires a different way of acting. Trop Med Int Health. 2005;10(12):1242-1250.

8. Haddis M, Jerene D. Awareness of voluntary-counseling and testing service among women attending antenatal care service at Arba Minch. Available from: http://www.ajol.info/viewarticle.php?jid=56\&id=2635 8\&layout=abstract. Accessed July 4, 2008.

9. Kominami M, Kawata K, Ali M, Meena H, Ushijima H. Factors determining prenatal HIV testing for prevention of mother to child transmission in Dar Es Salaam, Tanzania. Pediatr Int. 2007;49(2):286-292. 
10. Jebessa S, Teka T. Knowledge and attitude towards mother-to-child transmission and its prevention among post natal mothers in Tikur Anbessa and Zewditu Memorial Hospital, Addis Ababa. Ethiop J Health Dev. 2005;9(3):211-218.

11. Sandra M. Achieving Skilled Attendance for All: A Synthesis of Current Knowledge and Recommended Actions for Scaling Up. London, UK: Department for International Development Health Resource Centre; 2005.

12. Taffa N, Obare F. Pregnancy and child health outcomes among adolescents in Ethiopia. Ethiop J Health Dev. 2004:18(2):90-95.

13. World Health Organisation. National AIDS Program Management: A Training Course: Sub-module 6.5: Prevention of mother-to-child transmission. 2007. Available from: http://www.searo.who.int/hiv-aids. Accessed December 30, 2007.

14. Kloos H, Haile Mariam D, Lindtjørn B. The AIDS epidemic in a low-income country: Ethiopia. Human Ecology Review. 2007;14(1):39-55.

15. Piwoz EG, Ross JS. Use of population-specific infant mortality rates to inform policy decisions regarding HIV and infant feeding. J Nutr. 2005;135(5):1113-1119.

16. Bajunirwe F, Muzoora M. Barriers to the implementation of programs for the prevention of mother-to-child transmission of HIV: A cross-sectional survey in rural and urban Uganda. AIDS Res Ther. 2005;28:2:10

17. Bolu O, Anand A, Swartszendruber A, et al. Utility of antenatal HIV surveillance data to evaluate prevention of mother-to-child HIV transmission programs in resource-limited settings. Am J Obstet Gynecol. 2007:197(3 Suppl):S17-S25.
18. Creative Research Systems. Sample size formula for our sample size calculator. Available from: http://www.surveysystem.com/ sample-size-formula.htm. Accessed August 23, 2008.

19. Amberbir A, Deribe K, Lingerh W, Getachew B, Dejene Y. Uptake of voluntary counselling and testing (VCT) and correlates among women attending antenatal care (ANC): Implication to prevention of mother-to-child transmission (PMTCT) of human immunodeficiency virus (HIV), Southwest Ethiopia. Abstract presented at the Ethiopian Public Health Association XVIth annual conference, October 26-28, 2005, Addis Ababa, Ethiopia.

20. Federal Democratic Republic of Ethiopia. Report on Progress towards Implementation of the UN Declaration of Commitment on HIV/AIDS. Addis Ababa, Ethiopia: HIV/AIDS Prevention and Control Office; 2008 .

21. Msellati P, Hingst G, Kaba F, Viho I, Welffens-Ekara C, Dabis F. Operational issues in preventing mother-to-child transmission of HIV-1 in Abidjan, Cote d'Ivore,1998-1999. Bull World Health Organ. 2001;79(7):641-647.

22. Cartoux M, Meda N, Van de Perre P, Newell ML, de Vincenzi I, Dabis F. Acceptability of voluntary HIV testing by pregnant women in developing countries: An international survey. Ghent International Working Group on Mother-to-Child Transmission of HIV. AIDS. 1998;12:2489-2493.

23. Nigussie M, Hailemariam D, Mitikie G. Assessment of safe delivery service utilization among women of childbearing age in north Gondar zone, north-west Ethiopia. Ethiop J Health Dev. 2004;18(3):145-152.
International Journal of Women's Health

\section{Publish your work in this journal}

The International Journal of Women's Health is an international, peerreviewed open-access journal publishing original research, reports, reviews and commentaries on all aspects of women's healthcare including gynecology, obstetrics, and breast cancer. Subject areas include: Chronic conditions (migraine headaches, arthritis, osteoporosis);

\section{Dovepress}

Endocrine and autoimmune syndromes; Sexual and reproductive health; Psychological and psychosocial conditions. The manuscript management system is completely online and includes a very quick and fair peer-review system. Visit http://www.dovepress.com/ testimonials.php to read real quotes from published authors. 